\title{
ESTUDO DA INFLUÊNCIA DA TEMPERATURA DE AUSTENITIZAÇÃO E DE RESFRIAMENTO SOBRE A MICROESTRUTURA E DUREZA DO AÇO ABNT 4140 FORJADO A QUENTE*
}

André Rosiak ${ }^{1}$

Luana De Lucca de Costa ${ }^{2}$ Alberto Moreira Guerreiro Brito ${ }^{3}$

Lirio Schaeffer 4

\section{Resumo}

No processo de forjamento a quente, devido aos ciclos térmicos e mecânicos a que o material é submetido, diversos fatores influenciam e ampliam a gama de propriedades mecânicas que podem ser obtidas nas peças metálicas produtos deste processo. A proposta deste artigo é estudar a influência dos fatores tempo de austenitização, temperatura e deformação sobre a variação da dureza do aço ABNT 4140. Para isso, o material foi mantido em diferentes temperaturas, durante diferentes períodos de tempo e, posteriormente, forjado e tratado termicamente em patamares semelhantes aos de recozimento direto e revenimento. Esta pesquisa corresponde a uma das etapas do projeto BRAGECRIM (Iniciativa Brasil-Alemanha para Pesquisa Colaborativa em Tecnologia de Manufatura).

Palavras-chave: Propriedades mecânicas; Temperatura de austenitização; Deformação; Aço ABNT 4140.

\section{STUDY OF INFLUENCE OF AUSTENITIZATION TEMPERATURE AND COOLING ON THE MICROSTRUCTURE AND HARDNESS OF A HOT FORGED ABNT 4140 STEEL}

\section{Abstract}

In hot forging, several parameters influence and increase the range of mechanical properties that can be obtained in metallic parts due to thermo-mechanical cycling that the material is subjected. The goal of this paper is studying the influence of the austenitization time, temperature, and deformation on the hardness of an ABNT 4140 steel. The material was maintained at different temperatures for different times, forged and heat treated in similar conditions to the annealing and tempering treatments. This research corresponds to one step of BRAGECRIM project (BrazilGermany Initiative for Collaborative Research in Manufacturing Technology).

Keywords: Mechanical properties; Austenitization temperature; Deformation, Steel ABNT 4140

1 Graduando em Engenharia Metalúrgica na Universidade Federal do Rio Grande do Sul, Bolsista de Iniciação Tecnológica do Laboratório de Transformação Mecânica (LdTM), Porto Alegre, RS, Brasil.

2 Engenheira Mecânica, Mestre em Engenharia, Doutoranda do Programa de Pós Graduação em Engenharia em Minas, Metalurgia e Materiais, Professora no Instituto Federal do Rio Grande do Sul - Campus Farroupilha, Porto Alegre, RS, Brasil.

3 Engenheiro Metalúrgico, Doutor em Engenharia, Professor na Universidade Federal do Rio Grande do Sul, Porto Alegre, RS, Brasil.

4 Engenheiro Mecânico, Doutor em Engenharia, Professor na Universidade Federal do Rio Grande do Sul, Diretor do Laboratório de Transformação Mecânica (LdTM), Porto Alegre, RS, Brasil. 


\section{INTRODUÇÃO}

A mecânica de deformação plástica é apenas uma das maneiras de estudo da conformação plástica. Os outros tratamentos imprescindíveis são, por exemplo, os descritos por Bresciani (2011) ${ }^{1}$ :

- Metalurgia da deformação plástica, que se ocupa, essencialmente, na relação entre a capacidade do metal ser deformado e sua microestrutura;

- Microestrutura, e a influência dos tratamentos mecânicos, associados ou não aos tratamentos térmicos.

Assim, quanto a microestrutura, Padilha et al. (2005) $)^{2}$ afirma que durante a deformação plástica ocorrem eventos importantes, tais como:

- Ocorre mudança na forma dos grãos;

- A orientação dos grãos muda e eles geralmente adquirem orientação preferencial (textura de deformação);

- A quantidade de contornos de grão por unidade de volume aumenta;

- A quantidade de defeitos e discordâncias por unidade de volume aumenta de várias ordens de grandeza.

Tratando-se em especial o forjamento em matriz aberta, a mudança microestrutural ocorre, principalmente, pela deformação do material e pela recristalização dinâmica. O processo de recristalização dinâmica vem sendo investigado veementemente porque estar relacionado intimamente ao processo de conformação a quente, bem como, o rearranjo metalúrgico, a resistência à deformação a quente e a melhoria da capacidade de deformação.

No término da deformação ocorre o fenômeno de recuperação estática que restaura o material até certa proporção, a partir dos mesmos mecanismos da recuperação dinâmica, sendo que o seu amaciamento ou restauração total só ocorre com a recristalização estática. Esse fenômeno elimina as discordâncias de forma coletiva, com a nucleação e crescimento de novos grãos isentos de deformação. ${ }^{3}$

O estudo de Burke e Turnbull (1952) ${ }^{4}$, considerado referência mundial no estudo dos fenômenos metalurgicos da deformação a quente,, sintetiza o conhecimento sobre recristalização em 7 "leis", sendo elas: 1) É necessária deformação mínima para que a recristalização ocorra; 2) Quanto menor a deformação, mais alta é a temperatura para o início da recristalização; 3) Quanto maior o tempo de recozimento, menor é a temperatura necessária para que a recristalização ocorra; 4) O tamanho do grão final depende, principalmente, do grau de deformação e da temperatura de recozimento. 5) Quanto maior o tamanho do grão original, maior é a deformação necessária para que a recristalização se complete em um mesmo tempo de recozimento. 6) Para determinado grau de redução, quanto maior a temperatura de deformação, maior a temperatura de recristalização e maior é o tamanho do grão final; 7) O aquecimento continuado após a recristalização causa o crescimento de grão.

Em um material deformado a quente as propriedades finais são influenciadas pela natureza dos fenômenos metalúrgicos que ocorrem durante e após a deformação. Durante a deformação estão ocorrendo concomitantemente endurecimento e amaciamento dinâmico. O amaciamento dinâmico pode ser de dois tipos: recuperação dinâmica e recristalização dinâmica ${ }^{5}$. Devido à intensa vibração térmica que favorece a difusão atômica e a mobilidade e aniquilamentos das discordâncias, o encruamento e a estrutura distorcida dos grãos são rapidamente eliminadas pela formação de novos grãos livres de deformação em função dos processos de amaciamento dinâmico, que são termicamente ativados. ${ }^{2}$ 
Após a deformação, ocorrem processos de restauração e o consequente amaciamento do material. Existem três diferentes fenômenos que podem ser responsáveis por este amaciamento: recuperação estática, recristalização estática e recristalização metadinâmica. ${ }^{6}$

Diante do complexidade dos estudos dos fenômenos metalúrgicos na conformação a quente e da vasta gama de propriedades mecânicas influênciadas por eles, neste artigo estudou-se a influência dos fatores tempo de austenitização, temperatura, deformação e patamar térmico, a partir de análise microestutural, sobre esses fenômenos e, consequentemente, variação comportamental das curvas força versus deslocamento e na dureza do aço ABNT 4140 quando conformado em condições análogas ao forjamento a quente em matriz aberta.

\section{MATERIAIS E MÉTODOS}

Neste trabalho, corpos de prova cúbicos de $18 \mathrm{~mm}$ de aresta de aço liga ABNT 4140, foram submetidos a diferentes ciclos termomecânicos, baseados nos ciclos a que são submetidos os billets no processo de forjamento em matriz aberta para produção de eixos vazados, para aplicação em aerogeradores de energia. Utilizouse para fabricação dos corpos de prova aço ABNT 4140 na condição laminado. Nos corpos de prova foram feitos furos de $2 \mathrm{~mm}$ de diâmetro e comprimento de $9 \mathrm{~mm}$ no centro da face frontal para a fixação de termopar tipo $\mathrm{K}$.

Determinou-se rotas de ensaio: Aquecimento do forno até a temperatura de austenitização determinada; Inserção do corpo de prova sobre base cerâmica localizada na parte central do forno; Espera do tempo necessário para homogeneizar a temperatura, sendo que, foram mensurados tempos e temperaturas diferentes de aquecimento e permanência dos corpos de prova na condição de austenitização, conforme Tabela 1; Retirada do corpo de prova, com auxílio de uma tenaz adaptada para segurança e encaixe ideal; Compressão de $50 \%$ em altura, ou seja, $9 \mathrm{~mm}$, controlado por batentes e sistema de cursos da prensa. Após a compressão, inseriram-se os corpos de prova em um forno a $650^{\circ} \mathrm{C}$, onde permanecem por $20 \mathrm{~min}$, temperatura característica do tratamento térmico de recozimento para recristalização Em seguida, colocaram-se os corpos de provasobre bases refratárias e resfriam ao ar até a temperatura ambiente. A rota de aquecimento, conformação e resfriamento é representada na Figura 1. Os corpos de prova foram austenitizados em forno elétrico, marca SANCHIS, sobre placas cerâmicas, e foram realizaram-se ensaios de compressão em uma prensa hidráulica da marca EKA, modelo PKL40, com capacidade de 400 kN e velocidade de prensagem de $4,5 \mathrm{~mm} / \mathrm{s}^{-1}$. Lubrificaram-se os corpos de prova em solução a base de grafite. O deslocamento da matriz superior na prensa de modo a controlar a redução em altura foi obtido utilizando um sensor de deslocamento do tipo LVDT. Os dados de deslocamento foram adquiridos através de um sistema de aquisição da marca HBM, modelo Spider.8 conectado a Prensa, sendo a leitura dos dados realizada pelo software Catman.

Realizaram-se ensaios de microdureza em equipamento Microdurômetro, modelo Hardness Tester ISH-TDV 1000, marca INSIDE. Estabeleceu-se um padrão de 7 medidas no sentido vertical de cada amostra, sendo o valor obtido como dureza HV do corpo de prova a média dos valores obtidos.

$\mathrm{Na}$ revelação das fases nas micrografias, utilizou-se o método de imersão por, aproximadamente, $1 \mathrm{~min}$ em solução aquosa de $4 \mathrm{~g}$ ácido pícrico aquecidos e mantidos a $55^{\circ} \mathrm{C}$ por $1 \mathrm{~h}$. A solução aquosa de Nital $5 \%$ também foi testada, mas 
apresentou resultados inferiores. Capituraram-se as imagens em microscópio óptico invertido da marca OLYMPUS, modelo GX-51.

Tabela 1 - Representação da identificação das amostras conforme t e T de austenitização.

\begin{tabular}{c|c|c|c}
\cline { 2 - 4 } & $22 \min$ & $66 \min$ & $200 \mathrm{~min}$ \\
\hline $900^{\circ} \mathrm{C}$ & $1 \mathrm{~A}$ & $1 \mathrm{~B}$ & $1 \mathrm{C}$ \\
\hline $1000^{\circ} \mathrm{C}$ & $2 \mathrm{~A}$ & $2 \mathrm{~B}$ & $2 \mathrm{C}$ \\
\hline $1100^{\circ} \mathrm{C}$ & $3 \mathrm{~A}$ & $3 \mathrm{~B}$ & $3 \mathrm{C}$ \\
\hline $1200^{\circ} \mathrm{C}$ & $4 \mathrm{~A}$ & $4 \mathrm{~B}$ & $4 \mathrm{C}$ \\
\hline
\end{tabular}

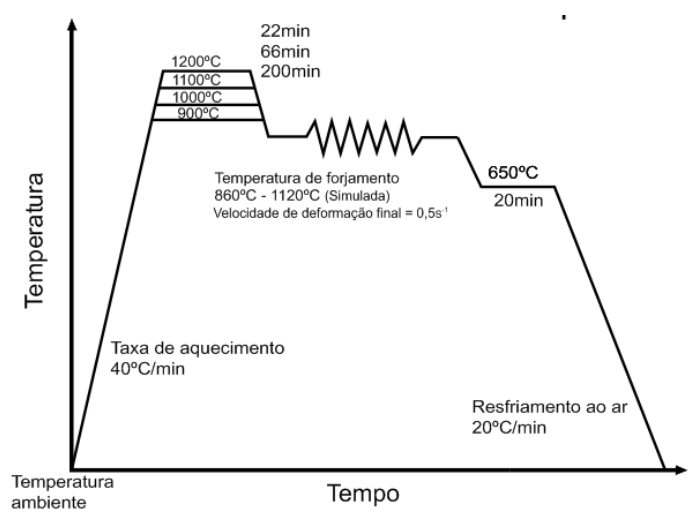

Figura 1 - Representação dos Ciclos Termomecânicos impostos aos corpos de prova.

\section{RESULTADOS E DISCUSSÃO}

Neste capítulo são apresentados resultados referentes aos ensaios realizados; à microestrutura formada e sua relação com propriedades mecânicas dos corpos de prova expostos às sequências de diferentes ciclos termomecânicos apresentados anteriormente.

\subsection{Ensaio Mecânico de Compressão}

Os ensaios de compressão evidenciaram a influência dos fatores temperatura e tempo de austenitização na força necessária para a conformação dos corpos de prova, conforme a Figuras 2, 3 e 4 .

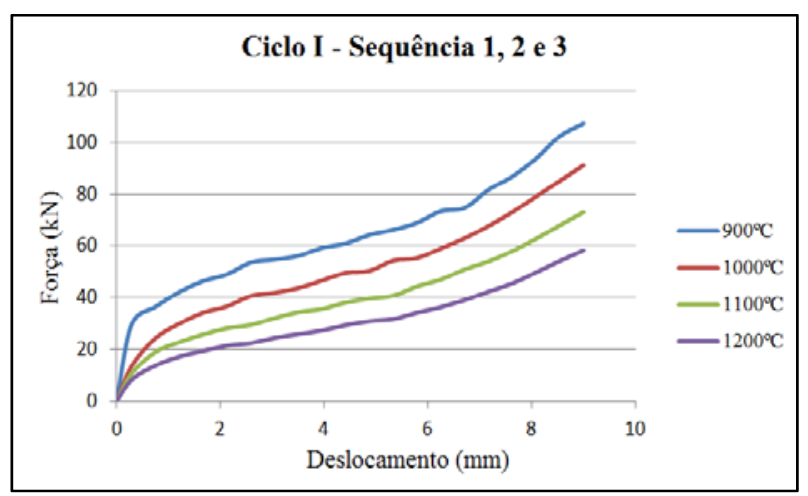

Figura 2 - Gráfico Força $(\mathrm{kN})$ versus Deslocamento $(\mathrm{mm})$. Tempo de austenitização de $22 \mathrm{mim}$. 
A Figura 2 apresentam os valores de força, em kN, para a redução em altura de 9 $\mathrm{mm}, 50 \%$, nas condições do Período I. Desta forma, para tempo de austenitização de 22 mim, são necessárias 107,2, 91,2, 73 e 58,4 kN para conformar os corpos de prova aquecidos a $900,1000,1100$ e $1200^{\circ} \mathrm{C}$, respectivamente.

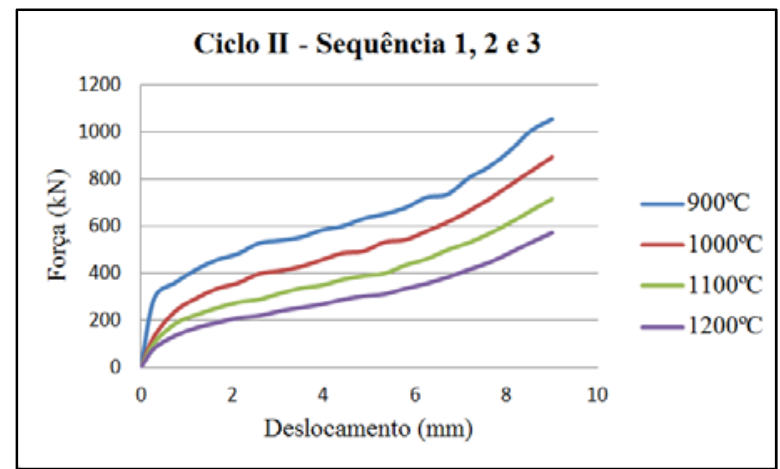

Figura 3 - Gráfico Força $(\mathrm{kN})$ versus Deslocamento $(\mathrm{mm})$. Tempo de austenitização de 66mim.

Conforme Figura 3, para o tempo de austenitização de $66 \mathrm{mim}$, são necessárias $108,1,89,4,71,2$ e $56,7 \mathrm{kN}$ para conformar os corpos de prova aquecidos a 900 , 1000,1100 e $1200^{\circ} \mathrm{C}$, respectivamente, assim, comparando os Períodos I e II, não houve grandes alterações quanto a força.

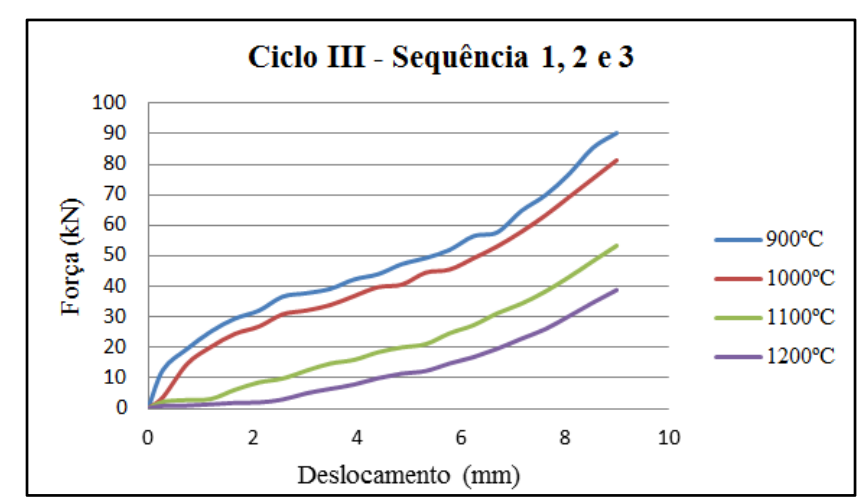

Figura 4 - Gráfico Força (kN) versus Deslocamento (mm). Tempo de austenitização de 200mim.

Já para o tempo máximo de manutenção nas temperaturas, 200 minutos, houve expressivas quedas na força necessária à conformação, sendo 90,2, 81,3, 53,3 e $38,8 \mathrm{kN}$ para as temperaturas de $900,1000,1100$ e $1200^{\circ} \mathrm{C}$.

Como frequentemente encontrado na literatura ${ }^{5,7,8}$, esses resultados remetem que a redução necessária à conformação é resultado da redução da tensão de escoamento, kf , do material que é função dependente da temperatura, além, da deformação verdadeira e velocidade de deformação condições de deformação a quente. A influência do fator tempo em que as peças foram mantidas nas referidas temperaturas dá-se pelo aumento do grão austenítico. Segundo Costa e Silva ${ }^{9}$, quando mais tempo os aços são mantidos a altas temperaturas, maior será o diâmetro médio dos grãos austeníticos, assim, menor às áreas de interface e maior mobilidade de discordâncias, facilitando a conformação a partir causando a diminuição da resistência mecânica e ao escoamento. 


\subsection{Microdurezas}

Os resultados referentes às durezas obtidas são reflexos dos tratamentos térmicos e mecânicos, termomecânicos, a que foram submetidos os corpos de prova. Assim, a obtenção desses resultados esta diretamente relacionada à microestrutura formada em cada corpo de prova e será discutida na próxima seção, sendo esta, apenas de apresentação dos resultados.

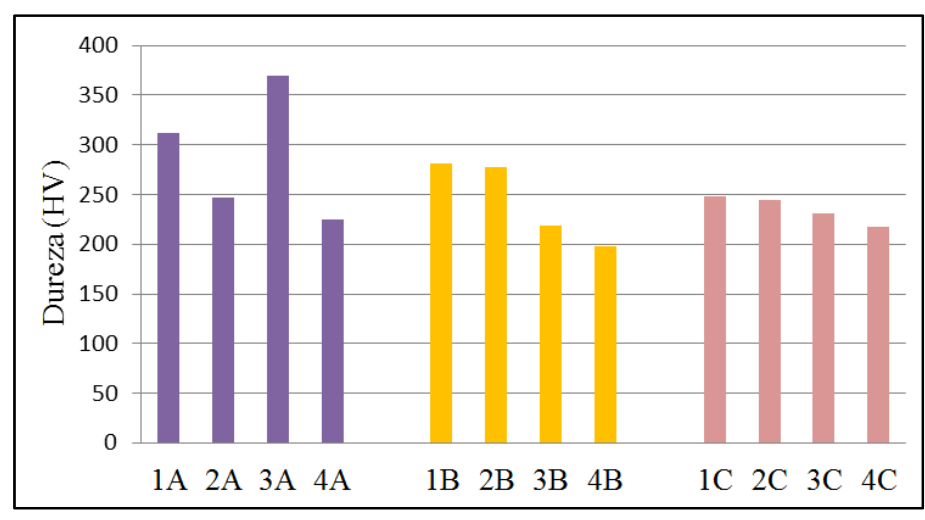

Figura 5 - Gráficos de Colunas das durezas (HV) .

Os Ciclos, após conformados, foram mantidos em forno à $650^{\circ} \mathrm{C}$, temperatura característica do tratamento térmico de recozimento para recristalização, conforme gráfico de patamares apresentado na Figura 2, sendo que a principal aplicação deste tratamento é a restauração da ductibilidade. Assim, foram obtidos: 312, 247, 369 e $255 \mathrm{HV}$ para os corpos de prova 1A, 2A, 3A e 4A, respectivamente. Durezas de 281, 277, 219 e 197HV para 1B, 2B, 3B e 4B. Já 247, 244, 230 e 217 HV para a numeração $1 \mathrm{C}, 2 \mathrm{C}, 3 \mathrm{C}$ e $4 \mathrm{C}$.

A análise e fundamentos desses resultados é feita na próxima seção.

\subsection{Micrografias}

Quanto às transformações de fase, a análise é feita com a utilização do diagrama de resfriamento contínuo do aço AISI 4140.

Todas as peças foram aquecidas acima de $750^{\circ} \mathrm{C}$, temperatura de completa transformação austenítica. E após a homogenizaçao da temperatura permanecem nesta região por 22, 66 e 200 minutos, sendo forjadas à aproximadamente, $860^{\circ} \mathrm{C}$, $910^{\circ} \mathrm{C}, 980^{\circ} \mathrm{C}$ e $1024^{\circ} \mathrm{C}$.

Depois de forjadas, são transferidas imediatamente (3s) para um forno a $650^{\circ} \mathrm{C}$, sendo a taxa de resfriamento aproximada $70^{\circ} \mathrm{C} / \mathrm{min}$, e permanecem nesta temperatura por 20 minutos. Esta rota de aquecimento e resfriamento, como mencionado nas análises de dureza, caracteriza as faixas de temperaturas do tratamento térmico de recozimento para recristalização.

Após o patamar de $650^{\circ} \mathrm{C}$, as peças resfriaram ao ar com taxa de resfriamento de aproximado de $20^{\circ} \mathrm{C} / \mathrm{min}$. Traçando as rotas de resfriamento no diagrama de resfriamento contínuo do aço AISI 4140 a partir da fase austenítica haverá formação de ferrita, austenita, bainita e perlita, sendo a porcentagem de austenita estimada menor que $1 \%$.

Observando as Figuras 7,8 e 9, identifica-se a presença de ferrita e perlita em todas as imagens, porém, distribuídas em formas e tamanhos distintos. Não é possível a identificação da austenita e da bainita devido a seus baixos percentuais. 
É conhecido, através de estudos do diagrama $\mathrm{Fe}-\mathrm{Fe} 3 \mathrm{C}$ e formação de microconstituintes, que a ferrita se origina nos contornos de grão da austenita e quando o limite de solubilidade do carbono na ferrita é atingido ocorre a precipitação da cementita, e as lamelas de ferrita e cementita crescem de modo colaborativo, formando a perlita.

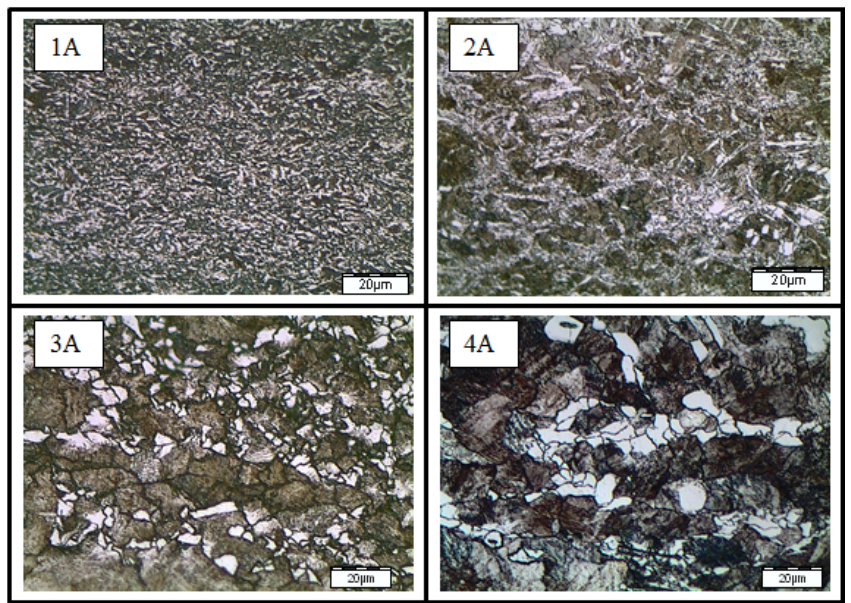

Figura 6 - Micrografias dos corpos de prova submetidos ao tempo de austenitização de $22 \mathrm{~min}$.

Quanto menor o grão ferrítico e espaçamentos interlamelares da perlita, mais duro será o aço. Esta afirmação pode ser observada na Figura 5 que apresenta os resultados de dureza referentes a estas amostras. Sendo que a $3^{a}$ é a que apresentou maior valor de dureza, $369 \mathrm{HV}$, tendo grãos ferríticos refinados e perlíticos uniformemente distribuídos nas bandas de transição. Com embasamento em Kwietniewski ${ }^{10}$, entende-se que a energia de deformação acumulada na ferrita deu inicio apenas a recuperação, que não é significativa devido ao pouco tempo de permanência da peça no patamar de $650^{\circ} \mathrm{C}$.

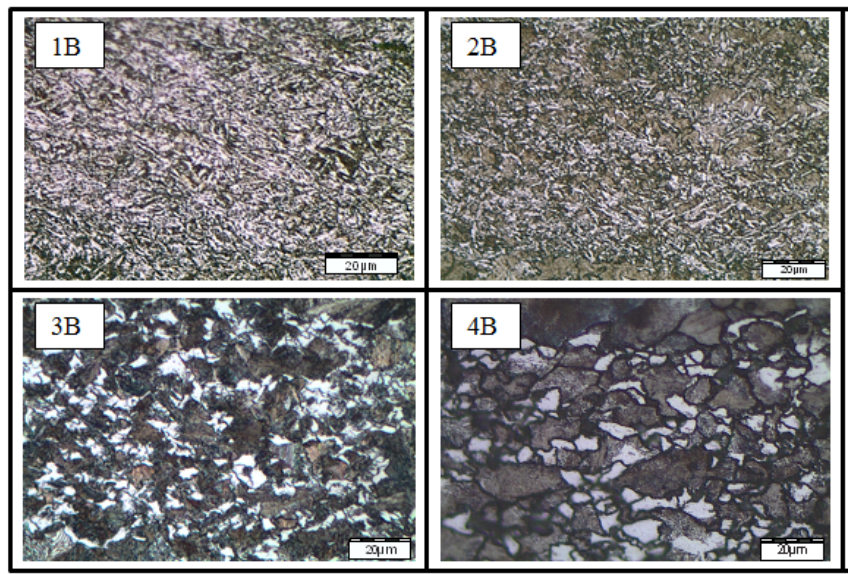

Figura 7 - Micrografias dos corpos de prova submetidos ao tempo de austenitização de 66min.

Amostras com grãos ferríticos maiores e distribuídos uniformemente aos perlíticos de lamelas espaçadas, como na amostra 4C, apresentaram as menores durezas, chegando a $197 \mathrm{HV}$.

A estrutura totalmente recristalizada, como na amostra 4F, transforma-se na estrutura 4C, assim, os grãos recristalizados crescem e caracterizam a estrutura dos grãos ferríticos nos contornos com percentuais próximos em tamanho aos perlíticos, causando amaciamento do aço, que passa de $580 \mathrm{HV}$ para $217 \mathrm{HV}$. 


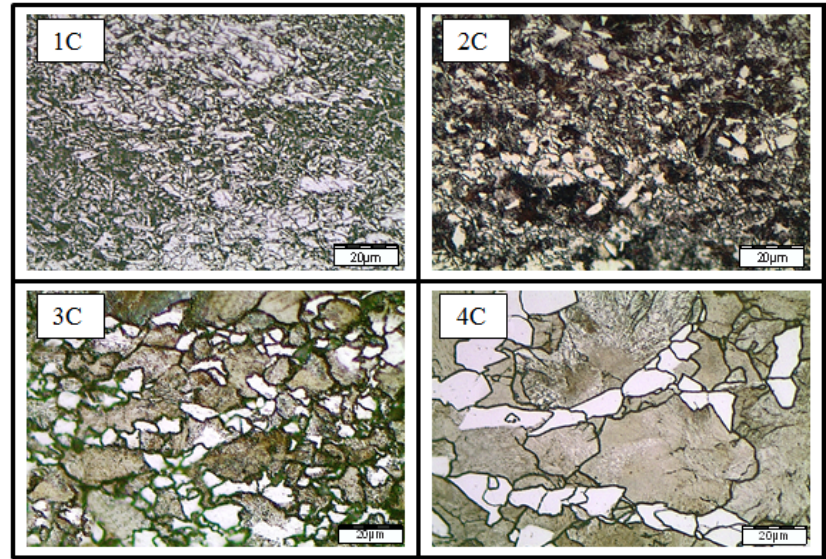

Figura 8 - Micrografias dos corpos de prova submetidos ao tempo de austenitização de 66min.

\section{CONCLUSÃO}

Este artigo assumiu como objetivo principal analisar o efeito de diferentes Ciclos termomecânicos na variação da dureza do aço ABNT 4140. As curvas Força (ton) versus Deslocamento $(\mathrm{mm})$ puderam ser analisadas e relacionadas aos fenômenos microestruturas decorrentes da conformação a quente, sendo que, tempos e temperaturas maiores de austenitização necessitaram de menores forças para a conformação. As formas como apresentaram as fases foram analisadas, concluindo que a disposição das fases e o tamanho de grão austenítico prévio, são as razões para altas durezas nas amostras $1 \mathrm{~A}$ e $3^{\mathrm{a}}$, sendo a microestrutura oriunda do menor tempo de austenitização $(22 \mathrm{~min})$ a $900^{\circ} \mathrm{C}$ e $1100^{\circ} \mathrm{C}$. Ainda, o patamar térmico estabelecido $\left(650^{\circ} \mathrm{C}\right)$ possibilita que os grãos se recuperem, sendo que, devido ao tempo de permanencia no patamar, a energia acumulada não foi suficiente para recristalização.

\section{Agradecimentos}

Aos orgãos de auxílio financeiro: Capes, CNPq e FAPERGS.

\section{REFERÊNCIAS}

1 Bresciani Filho, E., Silva, I. B., Batalha, G. F., \& Button, S. T. (2011). Conformação Plática dos Metais. $1^{\circ}$ Edição Digital -EPUSP, São Paulo, SP, Brasil.

2 Padilha, A. F., \& Siciliano JR, F. (2005). Encruamento, Recristalização, Crescimento de Grão e Textura. $3^{\circ}$ Edição, Ed: Associação Brasileira de Metalurgia e Materiais, ABMM, São Paulo, SP, Brasil.

3 Chen, M. S. et al. (2012). The kinetics of dynamic recrystallization of 42CrMo steel. Materials Science \& Enginnering A, $\mathrm{n}^{\circ}$ A 556, pp. 260-266.

4 Burke, J. E., \& Turnbull, D. (1952). Recrystallization and grain growth. Progress in Metal Physics, Vol. 3, pp. 275-292.

5 Jorge Júnior, A. M. (1997). Análise do Comportamento Mecânico de Aços Inoxidáveis em Altas Temperaturas e Altas Taxas de Deformação. Tese de doutorado Universidade Federal de São Carlos, São Carlos, SP, Brasil.

6 Regone, W. (2009). Acompanhamento da evolução microestrutural no forjamento a quente com matriz fechada por simulação física e numérica. Dissertação de Mestrado UNICAMP, Campinas, SP, Brasil.

7 Lin, Y. C., Chem, M. S., \& Zong, J. Effect of temperature and strain rate on the compressive. Journal of materials processing technology, Vol. 30, pp. 308-315. 
8 Schaeffer, L. (2001). Forjamento - Introdução ao Processo. Ed: Imprensa Livre, Porto Alegre, RS, Brasil.

9 Costa e Silva, M., \& MEI, P. R. (1981). Tecnologia dos Aços. Ed: Hambrug Ltda, São Paulo, SP, Brasil.

10 Kwietniewski, C. E., \& Kiss, F. J. (2013). Metalografia e Tratamentos Térmicos de Aços e Ferros Fundidos. Ed: UFRGS, Porto Alegre, Brasil. 